\title{
HEALTH STATUS OF WOMEN IN PAKISTAN: A RESEARCH STUDY FROM SAIDPUR VILLAGE OF FEDERAL CAPITAL AREA OF ISLAMABAD, PAKISTAN
}

\author{
Khalid Mahmood, Hufsa Farooq \\ Department of Pakistan Studies, Allama Iqbal Open University, Islamabad, Pakistan
}

\begin{abstract}
Background: The women make half of population of Pakistan which should not be neglected in any case. The women of the country are kept backward in our culture, due to which they are unable to participate in various fields of life which also affects their health. The objective of this study was to find the socio-economic, sociocultural, and religious determinants that contribute to the poor health status of women.

Materials \& Methods: This qualitative study was conducted in Department of Pakistan Studies, Allama lqbal Open University, Islamabad, Pakistan from April to July 2019 through in-depth interviews from middle and lower middle class married women form Saidpur village of Islamabad. The sample size was 32 couples (64 individuals).

Results: Major factors that are responsible for the poor health status of women are restrictions on the mobility of women, violence against women, and financial dependence. Women in the Saidpur village are not allowed to avail healthcare opportunities without permission of their male family members, even they are depended on men financially to visit a doctor. Moreover, violence against women including physical, emotional, and mental is another primary cause behind the poor health status of women in Saidpur village.

Conclusion: In Pakistan, a large number of women are deprived from quality health. The causes include poverty, lack of food, unavailability of education and violence on women. Moreover, the issue of gender inequality is also uncontrolled element which strongly affects the women's health. The civil society, media and the government should take their responsibility to remove the problems which are faced by the women of Pakistani society regarding their health.
\end{abstract}

KEY WORDS: Women; Health; Patriarchy; Education; Illiteracy; Decision Making; Economic Status; Violence; Anxiety; Pakistan.

Cite as: Mahmood K, Farooq H. Health status of women in Pakistan: a research study from Saidpur village of federal capital area of Islamabad, Pakistan. Gomal J Med Sci 2018 Oct-Dec; 18(4): 141-7. https://doi.org/10.46903/ gjms/18.04.911

\section{INTRODUCTION}

1.1 Background: Pakistan is a developing country facing several social challenges, economic woes, and political troubles. It is the fifth most populated country in the world and ranked at $152^{\text {nd }}$ position out of 189 countries as per Human Development Index of United Nations Development Index 2018. ${ }^{1}$ Rising poverty, the higher rate of illiteracy, economic underdevelopment among others are considered as main hurdles in the social, economic, and political development of the

\section{Corresponding Author:}

Dr. Khalid Mahmood

Lecturer, Department of Pakistan Studies

Allama Iqbal Open University

Islamabad, Pakistan

E-mail: khalid.mahmood@aiou.edu.pk

Date Submitted: 11-03-2020

Date Revised: $\quad 20-07-2020$

Date Accepted:

$12-08-2020$ country. In addition to it, the status of women is discriminatory and marginalized in Pakistan as it is shown by its performance on global indexes. For instance, in the World Economic Forum 2019's Global Gender Gap Index, Pakistan ranked 151 out of 153 countries with standing at 149 in health and survival along with lower economic participation and lower literacy level. ${ }^{2}$ There is a strong relationship between the socioeconomic status of women and their health. While addressing women's lives, it is crucial to examine the underlying social, cultural, environmental, epidemiological, and economic determinants of health. ${ }^{3}$ Women with higher socioeconomic status enjoy good health as compared to those with lower socioeconomic status. For instance, malnutrition, stress, anxiety, and depression are directly linked to poverty because it prohibits people from fulfilling seeking healthcare. Women are victims of gender inequalities due to social, economic, and political disparities between men and women in Pakistan. Patriarchal practices are still dominant in Pakistani society, where 
very few women enjoy their fundamental rights and have access to socioeconomic resources and opportunities. The dominant role of men is not only keeping women subservient and subordinate but also poses the physical and mental health challenges for women. For instance, men's violence against women, mainly exercised by men to subordinate women using their advantageous position in society, often results in physical and mental health problems of women. Further, patriarchal society provides gendered access to resources and opportunities and it limits the fundamental rights of women including health. The patriarchal structure in Pakistani society restricts the mobility and freedom of women especially in tribal areas of Pakistan. In this way, women are unable to access healthcare facilities without the permission of men. In Pakistan, most of the fundamental rights are not practically available to women such as education and inheritance rights, etc. On the one hand, Pakistan has very limited female medical staff due to restrictions on women's education and on the other hand, socio-cultural and religious norms restrict women to be examined by male doctors because it violates the cultural and religious concept of seclusion or Pardah. Mainly, in the rural areas and slums of Pakistan, people in general and women, in particular, have to face poor health conditions. It is because of poverty, bad living conditions, and insufficient healthcare facilities in these areas. Predominantly, women of lower-class have been facing supplementary health issues, because of their low socioeconomic status in addition to inadequate healthcare facilities and poverty. Thus, women in Pakistan are facing different types of health issues caused by socioeconomic, cultural, and religious factors and because of these reasons they are unable to fulfill the responsibilities of their households and children as well as other spheres of life.

1.2 Justification of the study: The current study reflects upon the health status of women in Pakistan as the poor health of women. The women's poor health is an extremely significant issue because women are important in society as men. The females comprised around half of the total population of Pakistan. The development of any country depends upon the empowerment of women while the women's empowerment depends on their good health condition, including other factors. The whole nation's health status is depending upon the health of women.

'Women's health is an example of population health, the health of a specifically defined population. If the women are healthy, they will produce healthy children and thy may be able to take care of the entire family health, so we can say that healthy women are the sign of a healthy nation. ${ }^{4}$

1.3 Significance of the Study: This research has highlighted the health problems of lower-class women in Saidpur village in particular and the country in general. No study is carried out on the health issues of women in Saidpur. It will explore the determi- nants of the poor health status of women and the implications of poor health on women's status and overall development of Pakistan. However, studies on women's health exist, but the role of socio-economic and socio-cultural factors has not been paid much attention. The research provides a significant data regarding the women's health status in Pakistan and will extend the knowledge related to women's health.

The literature review is the origin of quality research because literature review helps in finding gaps in existing knowledge. After reviewing existing literature, it is found that extensive data is present on the reproductive health of women, that primarily focuses on biological factors but very little attention is given to the general health problems of lower-class women in Pakistan. This study uses existing literature collected from different resources to find out and explore the underlying factors behind the poor health status of women. The existing literature suggests that socioeconomic, religious, and socio-cultural factors along with biological and environmental factors impact the health condition of women. Women's biological factors, low socioeconomic status, psychological factors, inequalities, male dominant role, their living and working conditions, and lack of decision-making power are key determinants for women's ill-health. Moreover, the female of society has shortage of access to healthcare facilities to obtain healthcare. ${ }^{5}$

Women's health as an academic subject arose from the second wave of feminism and the women's health movement in 1970s. In which medicine was considered as a patriarchal institution. The main thoughts of the health movement included criticism of the male dominancy in the medical profession, the creation of medical knowledge about women's health, and the improvement of health services for women. Mostly the issues of women's health had been neglected. The feminists struggled for the establishment of separate health facilities for women. They mainly focused on women's physical health and in 1980s they used empiricist research to find gender differences in health to find out reasons for women's poor health. New knowledge related to women's health was added to existing knowledge and men's health was used as standardized measure. The role of social class inequalities in health was uncovered by using education as an overall measure for determining women's health status. In 1990, researchers focused on women's material resources and the effect of the structural context of women's living conditions for determining their health. ${ }^{6}$ The women's health movement also raised the matters of reproductive education and hospitals started to establishing separate women's health centers. Up to the present time, feminists are advocating for health facilities and policies related to reproductive freedom, contraceptive use and related issues related to women's health. ${ }^{7}$ 
1.4. Objectives of the study: The main objective of the study was to investigate and find out the determinants of the poor health of Pakistani women, particularly lower-class women. To examine the social, cultural and religious factors, which contribute to gender disparities in health. It will also explore how the poor health of women affects their position in society and development of the country. This study will help to highlight the range of issues facing by a woman in approaching health facilities and what role is played by their males in it.

\section{MATERIALS AND METHODS}

2.1 Participants: This qualitative study was conducted at the Department of Pakistan Studies, Allama Iqbal Open University, Islamabad, Pakistan from April 2019 to July 2019. The target population of this research study was the married couples in the Saidpur village in Islamabad. Most of the women in this region belong to the lower class and lower middle class.

2.2 Sampling Procedure: Convenience non-probability sampling technique was adopted. The sample size was 32 couples from the Saidpur Village in Islamabad.

2.3 Data collection: It involved a variety of methods such as observation and interviews. During informal discussions and formal interviews, respondents were asked questions about their ill-health experiences. The audio recording was also used as supplementary tool for researching to avoid interruption during interviews and discussions. Informal discussion and research provided detailed information.

\section{RESULTS AND DISCUSSION}

3.1 Cultural Obstacles: Men having cultural, political and economic supremacy exercise their decision-making authority over women. The study revealed that most males restrict the mobility and freedom of females. For instance, wives are not even allowed to visit their parent's homes without their husbands' permission. One of the respondents said during the interview;

"It is our culture, and everyone is familiar with this thing that only a man has decision making power in our family. Even, whenever I want to go to my parents' home, located in the same colony, I use to ask my husband first. We are strictly prohibited to go anywhere alone and without his permission."

Moreover, lower-class women in Pakistani society, depend on male members of the family to receive appropriate and adequate health care for their illnesses. These restrictions hinder female from getting the proper medication in case of illness. As another respondent told that;

"I have 3 children; still my husband does not allow me even a single time to go to the doctor alone. He usually sends me to the hospital along with his sister and mother"
Furthermore, women in Saidpur village also said that due to the responsibilities of men to earn for their families, they show neglect towards women's health. This leads women to major psychological and physical health issues which in many cases remain undiagnosed. Additionally, the cultural background of gender roles blinded women from recognizing their right to maintain good health. Mostly women considered their right to good health as unimportant and always rush to take care and meet the needs of other members of the family at the cost of their own physical health and well-being.

3.2 Violent Attitude towards Women: The violent treatment of men towards their women impacts their physical and mental health, and even some times results in the death of women. Many women in Saidpur village have experienced psychological and physical violence from their intimate partners. Gender-based violence includes physical abuse, mental abuse, emotional abuse and sexual abuse of women. Gender-based violence is a major public health problem and recognized as a violation of human rights. Men's violent behavior against their partners is not considered violent by society. It is considered normal behavior in Pakistani society, especially in rural areas. In most of the cases, women do not complain about the bad behavior of their husband because of social stigma as one of the respondents expressed her feelings in the following words:

"When I complained to my mother about my husband's violent behavior, she replied, this is not a new thing, your father did the same thing to me but as the time passes, I compromised with the things and you also have to compromise to save your house and for the better future of your children."

Intimate partner violence not only creates health issues for women but also greatly influences the mental health of children. The mental and physical illness of the mother put a drastic effect on children's personalities. The unhealthy mother faces a lot of difficulties in rearing and caring for children. One of the respondents having three children said,

"Whenever I feel mentally upset due to any reason, I cannot give proper time to my children, without any reason I get angry at them and all this happens just because of my mental or physical illness."

Violence is used as the main tool for the subordination of women by men and contributed to the poor health status of women. Women experience violence from their partner, other members of family, and strangers in public places. The main reasons behind men's violent behavior against women are illiteracy, the experience of child abuse, exposure to violence against their mothers, excessive use of alcohol, and a sense of domination over women. Further, reasons behind women who experience violence are illiteracy, exposure to violence against their mothers, 
the experience of abuse during childhood, attitudes accepting violence and their subordinate position. ${ }^{8}$ The health consequence of gender-based violence includes death, suicide attempts, chronic pains, mental health issues, reproductive health issues and other physical health issues. In addition to it, depression, anxiety, stress, fear, and other negative psychological issues occur. It is endorsed by sociocultural and religious beliefs.

The forms of violence existing in Pakistani society are dowry deaths, acid attacks, wife-battering, forced prostitution, honor killing, domestic violence, etc. Violence against women includes rape, gang rape, sexual mutilation, sex slavery, intimate partner violence, sex trafficking, aggravate in the situation of conflict and disasters, and the aftermath of disaster and conflict. ${ }^{9}$ The violence against women affects their general wellbeing by creating severe health problems. It also prevents women from fully participating in society. Moreover, women who experience violence face difficulties in approaching the criminal justice system owing to financial constraints for legal expenses. If a woman filed a complaint against violators, it also cost huge legal expenses and women are unable to bear these due to their economic dependency on males. At the national level, it impacts the national budget and the overall development of the country. Violence also restricts women's ability to access education, participation in economic activities and political as well as public life.

3.3 Responsibilities of Women: Women are considered as caretakers for their families and children. Ignorance of their own health while taking care of others can lead to the development of malnutrition in women. ${ }^{10}$ The majority of women in Saidpur village have the view that it is generally considered in their society that female gender has the sole responsibility to manage household activities, whether their health is good or not. Besides women's own ignorance, the lower socio-economic position of women creates a situation that can lead to ill-health of women as inadequate and low-quality food along with gender disparities within their families resulted in malnutrition of women. Gender inequalities in nutrition in Pakistani families caused the nutritional deprivation of women and female children. For instance, women and female children are malnourished especially of low-income families due to preference in food distribution given to male members of families. It is because men are considered as breadwinners of their family and women's unpaid work in the household is not considered as productive. It is generally believed that women do not need much food as men because of their limited role in the economic activities. However, the female are the source of reproduction of their offspring but this virtue of the women in not considered in the society. On the other hand, women's participation in agriculture, livestock, poultry, etc. usually remains unrecognized. Also, low-income families cannot afford sufficient and quality food for their families. Inflation along with food insecurity are also contributed to an increase in poverty and consequently poor health of the women. Thus, malnutrition leads to the prevalence of health problems of women in Pakistan, and inadequate nutrition not only affects the health of women but also the health of their children.

3.4 Illiteracy and Ignorance: During the research, it was found that several women were deprived from formal education in Saidpur village due to poor economic conditions, early marriage, lack of interest in education, etc. Education has been widely recognized as the most pivotal determinant of change in the personality development of an individual. It plays a crucial role in generating awareness about health. It is also closely related to women's health, nutrition, and fertility. Women's education makes them able to participate in decision-making about themselves, including their health. Further, educated women use more healthcare facilities than illiterate women. For example, more educated women usually use contraceptives than illiterate women. Generally, the children of educated mothers are healthier than uneducated ones. Literacy also influences the childbearing patterns and it helps in combating different health challenges. It is generally believed that people with higher literacy rates enjoy good health because of their health awareness than illiterate people. Health disparities increased when technology was introduced and uneducated people were unable to use technology. Due to illiteracy, women do not know how to prevent and treat diseases and infections. Due to less education and less awareness, uneducated people are unable to realize and understand their health problems. The increase in education leads to a decrease in health problems and improvement in the social status of women.

In the light of Pakistan Economic Survey, the literacy rate of the country is 58 percent including men and women. However, the ratio of male and female is 70 and 48 percent respectively. ${ }^{11}$ It shows that the female literacy rate is very low, particularly, in rural and tribal areas of Pakistan. Therefore, the majority of women in Pakistan are illiterate and the low level of educational attainment adversely influences the health of women and their children. In Pakistan, the social practice restricts females from pursuing education because women's education is not considered as important as male are considered as the breadwinner of the family. Early marriages, parents' illiteracy, and terrorist attacks have a long-lasting influence on women's education and consequently on their health. Discrimination against women in access to education results in a lack of access to decision making about their health. Similarly, inadequate female medical staff particularly is the outcome of restrictions on women's education and social customs. Further, in rural and tribal areas 
women are prohibited to be visited by male doctors. Along with this, religious belief also forbids women to be treated by male doctors because it violates the concept of Pardah. Social needs for women's reproductive health capacities are under this strict control of Pardah, which restricts women's medical care. The dominant role of male and cultural traditions may lead to gender inequalities in healthcare services. ${ }^{12}$ The lack of access to education is not only linked with the ill-health of women but it also leads to marginalization and disempowerment of women. Gender inequality in education leads to the economic and social underdevelopment of the country. Women's low health, social, economic, and educational status further their subordination and marginalization in society.

3.5 Poor Reproductive Health: Furthermore, uneducated women's ignorance of health-seeking behavior can lead to a much higher risk of suffering from reproductive and other health problems. ${ }^{13}$ According to the State of World Population 2019 report, Pakistan's maternal mortality rate is 178 per $100,000 . .^{14}$ These indicators show the neglecting of the reproductive health of women in Pakistan which results in severe health problems for women and their children. The poor reproductive health of women is also evident from the infant mortality rate that is 60.219 deaths per 1000 births. Major reasons for the high mortality rate is illiteracy, poverty and lack of facilities for family planning and other healthcare services in those areas. Problems in access to health facilities due to financial constraints, distant healthcare facilities, and delayed decision making are key causes of high maternal and infant mortality rates. Additionally, most women have problems while discussing the health problem as STD and HIV/AIDS due to social and cultural constraints also, because of limited knowledge about the vulnerability of the problem. Ignorance towards these issues affects the reproductive and sexual health of women and this may result in incurable diseases. Moreover, Pakistan's fertility rate remains high as about 3.488 births per woman. The higher fertility rate is not only risky for women's and children's health but also poses great challenges for the country. Higher population growth is the biggest challenge for Pakistan due to its scarce resources and economic crises. Rapid population growth impacts the development by aggravating economic, environmental, governmental, and political challenges for Pakistan. Higher population growth has implications for the social and economic development and wellbeing of its people due to its limited resources.

Moreover, insufficient health facilities in rural areas are another factor responsible for the poor health position. Even though 70 percent of the population lives in rural areas, most of the medical personal and health facilities are found in cities. ${ }^{15}$ In Saidpur village, women usually visit the only clinic in the village for the treatment of illnesses. This is one room clinic in which Dr. Mian Haris Masood sits six days a week except for Sunday. He is a physician in Polyclinic Islamabad.

The $18^{\text {th }}$ amendment of the constitution of Pakistan was a landmark event in the constitutional history of Pakistan. It is because the rights of health, education, amongst others, were included as a fundamental right. Prior to this, health was not recognized as the constitutional right of citizens of Pakistan in the constitution of 1973. Pakistan's healthcare system is comprised of the public and private sectors. Healthcare facilities of the public healthcare sector have been deteriorating and the private healthcare sector is performing better than the public healthcare system in terms of service quality and patient satisfaction, with 70 percent of the population being served by the private health sector. ${ }^{16}$ The private healthcare system of Pakistan includes private hospitals, clinics, and diagnostic labs. It is due to the better performance of the private sector; people opt for the private health sector rather than the public healthcare sector for their treatment. However, the people who belong to lower socioeconomic group or class are unable to bear private healthcare expenses and have lack of access the private healthcare services due to distant locality. Therefore, the bad performance of the public healthcare system is one of the key factors in the overall poor health status of low-income class especially of women of Pakistan.

In addition to it, the healthcare sector system in Pakistan is facing numerous challenges, such as the shortage of skilled and qualified human resources in the healthcare system. There are limited female service providers in rural areas, especially in tribal areas. The majority of women in these areas are not allowed to be treated by male doctors. The poor quality of the public healthcare sector is another problem for the declining health status of women. Additionally, owing to the distant locality of health services in rural areas, people are unable to access these facilities. Along with this, in remote areas, the absence of doctors and other medical staff at healthcare centers is one of the main problems of the public healthcare sector. Likewise, limited budget for the healthcare sector, inconsistent government policies on health rights, women's limited participation in health planning and implementation, and inadequate infrastructure and lack of use of advanced technological solutions for the treatment of patients resulted in the poor health status of the population, particularly, women of Pakistan.

\section{CONCLUSION AND RECOMMENDATIONS}

It has revealed that women of Saidpur Village at Islamabad have been facing several health problems. Socio-economic constraints limit women's access to information, and knowledge about health services. Also, public healthcare sector may contribute to im- 
prove women's health. From the above discussion, it is clear that in Pakistan, women are victims of poor health due to their low socio-economic status and religious and cultural constraints, along with the poor health system of Pakistan. The issues of male preference, poverty, discrimination against girls in food distribution, lack of education, restrictions on freedom and mobility, violence against women, and no implementation of health policies; all of these contributed to the ill-health of women. Women in Pakistan are guaranteed gender equality by the Constitution of Pakistan 1973 but disparities in all walks are still prevailing in Pakistani society. Despite constitutional amendments, which grant health right to all citizens without any discrimination, the situation of health of women particularly belonged to low-income families and rural areas is deteriorating. It is also argued that the position of women's health is interlinked with the concept of Pardah and other cultural constraints on freedom and mobility. Besides these factors, poverty, illiteracy, and discrimination are the prime causes of the poor health of women. Hence, issues of deteriorated health of women have strong links with the issue of gender inequality. To improve women's health positions, it is needed to take the above-mentioned measures. It is essential to establish gender equality in all respects of life for the wellbeing of women.

The present research has mainly focused on socio-economic, socio-cultural, and religious reasons behind the poor health of women in Saidpur village in Islamabad, Pakistan. There may be some limitations in this study regarding some other issues of women. It is a research study based on interviews and observational studies in only sole model village of Islamabad. Although, women in Pakistan are facing common health problems; factors that influence their health varies from culture to culture and region to region. Secondly, results are limited due to its sample size and these results could not be generalized on overall women in Pakistan. However, research can shed light on a limited set of aspects and there is a hope for improvement in this particular topic as it does not provide biological and environmental causes behind the health problems of women. It created a set of questions which can guide future study in this research area. Directions for future research should be based on the above-mentioned limitations in this research project and be addressed in the future.

In order to overcome identified issues of women's health, there is a dire need to raise awareness about women's health through electronic media, print media, and social media. As the health of the whole population is dependent on the health of women, the government must take steps for the alleviation of poverty from the country as well as for the well-being of citizens, especially women, who are discriminated against and marginalized. The government needs to implement health policies and take measures to practically giving women's fundamental rights such as education and inheritance rights. Women's good health condition not only empowers women by improving their living, educational, and economic circumstance but also pave a way for the development of the country. These issues must be addressed through tolerance and support in the institution of the family. There is a need to raise the level of awareness among women about health and the availability of the services. Moreover, programs about reproductive health should be enhanced to raise knowledge about health issues related to women.

Additionally; to improve this situation, the public hospitals should be provided in rural areas with adequate and qualified medical staff. Sufficient medicines and equipment with the latest technology should be provided for a better healthcare facility. An increase in healthcare budget at the national and provincial levels is needed for quality healthcare services. Programs related to healthcare should be launched for the awareness of social and cultural aspects of health. Mental health must be given proper attention as it plays an important role in the ill-health of women. The government should also take practical steps for posting doctors in rural areas.

\section{REFERENCES}

1. Haider M. Human Development Index 2019: Pakistan ranks lower than all South Asian countries. [The News online]. 2019 December 13 [cited 2021 March 22]. Available from: https://www.thenews. com.pk/print/582826-human-development-index2019-pakistan-ranks-lower-than-all-south-asiancountries

2. World Economic Forum. The Global Gender Gap Report 2020 [published 2019 Dec 16, cited 2020 Mar 22]. pp.9. Available at: https://www.weforum. org/reports/gender-gap-2020-report-100-yearspay-equality

3. Marmot M, Friel S, Bell R, Houweling TA, Taylor S. Commission on Social Determinants of Health. Closing the gap in a generation: health equity through action on the social determinants of health. Lancet 2008 Nov 8; 372 (9650):1661-9. https://doi.org/10.1016/S0140-6736(08)61690-6

4. Ronaq S. Why Women's health is a serious issue in Pakistan. Sharnoff's Global Views online [uploaded 2014 February 25, cited 2020 April 12]. Available from: https://www.sharnoffsglobalviews. com/health-women-pakistan-217/

5. Ravindran, TK Sundari. Gender issues in health projects and programmes. Oxford, UK: Oxfam GB, 1995. [cited 2020 March 11]. https://doi. org/10.3362/9780855987510.000

6. Riska E. Women's health: Issues and prospects. Scand J Public Health 2000 Jun; 28(2): 84-7. https://doi.org/10.1177/140349480002800202

7. Collins JB. Redefining Women's Health. American J Nursing 1995 Oct; 95 (10): 16Q-16S. https://doi. org/10.2307/3471344 
8. United Nations. Declaration on the elimination of violence against women. New York: United Nations. [cited 2020 January 19]. Available from: https://www.un.org/en/genocideprevention/documents/atrocity-crimes/Doc.21_declaration\%20 elimination\%20vaw.pdf

9. Violence against women in war: rape, AIDS, sex slavery. International. AIDS Wkly Plus 1996 Nov 25-Dec 2; 13-4. Available from: https://pubmed. ncbi.nlm.nih.gov/12347566/

10. Ilyas U, Kousar P. Malnutrition and its associated risk factors among women of reproductive age in rural community of Lahore. Int J Med Res Health Sci 2019;8(3):173-8.

11. Alvi M. Pakistan's literacy rate stands at 58pc. The News 2018 April 27. [cited 2020 Apr 19]. Available from: https://www.thenews.com.pk/print/309775pakistan-s-literacy-rate-static-at-58pc

12. Aborigo RA, Reidpath DD, Oduro AR, Allotey P. Male involvement in maternal health: perspectives of opinion leaders. BMC Pregnancy Childbirth 2018;18(3):1-10. https://doi.org/10.1186/s12884017-1641-9

13. Mahmood N, Durr-e-Nayab, Hakim A. An analysis of reproductive health issues in Pakistan. The Pakistan Development Review 2020;39(4):67593. https://doi.org/10.30541/v39i4llpp.675-693

14. Sathar Z. Saving Pakistani Mothers. [The Dawn online] 2019 May 12 [cited 2020 January 29]. Available from: https://www.popcouncil.org/news/ dawn-saving-pakistani-mothers

15. Zaidi S, Sahibzada S. Issues in Pakistan's health sector. The Pakistan Development Review 1986;25(4):671-82. https://doi.org/10.30541/ v25i4pp.671-682

16. Akbari, Ather H, Rankaduwa WR, Adika KK. Demand for public health care in Pakistan. The Pakistan Development Review 2009;48(2):141-53. https://doi.org/10.30541/v48i2pp.141-153

CONFLICT OF INTEREST
Authors declare no conflict of interest.
GRANT SUPPORT AND FINANCIAL DISCLOSURE
None declared.

\section{AUTHORS' CONTRIBUTION}

The following authors have made substantial contributions to the manuscript as under:
Conception or Design:
$\mathrm{KM}, \mathrm{HF}$
Acquisition, Analysis or Interpretation of Data:
$\mathrm{KM}, \mathrm{HF}$
Manuscript Writing \& Approval:
$\mathrm{KM}, \mathrm{HF}$

All the authors agree to be accountable for all aspects of the work in ensuring that questions related to the accuracy or integrity of any part of the work are appropriately investigated and resolved. 